\title{
Clinical case of surgical treatment of patient with rheumatoid forefoot deformity
}

\section{Introduction}

\section{Diagnosis}

Right forefoot deformity: hallux valgus, fixed $2^{\text {nd }}$ and $3^{\text {rd }}$ hammertoes. 1MTP joint arthritis of III stage. Rheumatoid seropositive erosive arthritis, low activity.

\section{Anamnesis morbid}

patient suffers from rheumatoid arthritis from 2013. After the beginning of the disease patient noted the progressive forefoot deformity. During last 2 years the big soft tissue formation appeared near the medial side of the 1 MTP joint of the right foot. In 2018 the patient was consulted in VA Nasonova Institute of Rheumatology, the surgical treatment was recommended.

\section{Rheumatoid arthritis therapy}

Methotrexate $10 \mathrm{mg}$ per week, effective.

\section{Operation}

Removal of the soft tissue formation, 1 MTP joint arthrodesis, resection of the $2^{\text {nd }}$ and $3^{\text {rd }}$ toes bocks of the right foot.

During the palpation there were the signs of fluid inside the formation. After the triple processing of the operation field with an antiseptic, a puncture of the subcutaneous soft tissue formation was performed, a viscous liquid of yellow color was evacuated, the material was taken for cytological examination. On the medial side in the area of 1 MTP joint the lens-shaped incision of $8 \mathrm{~cm}$ in length was performed. A voluminous soft tissue formation with small yellow inclusions, welded to the capsule and occupying the joint space, was
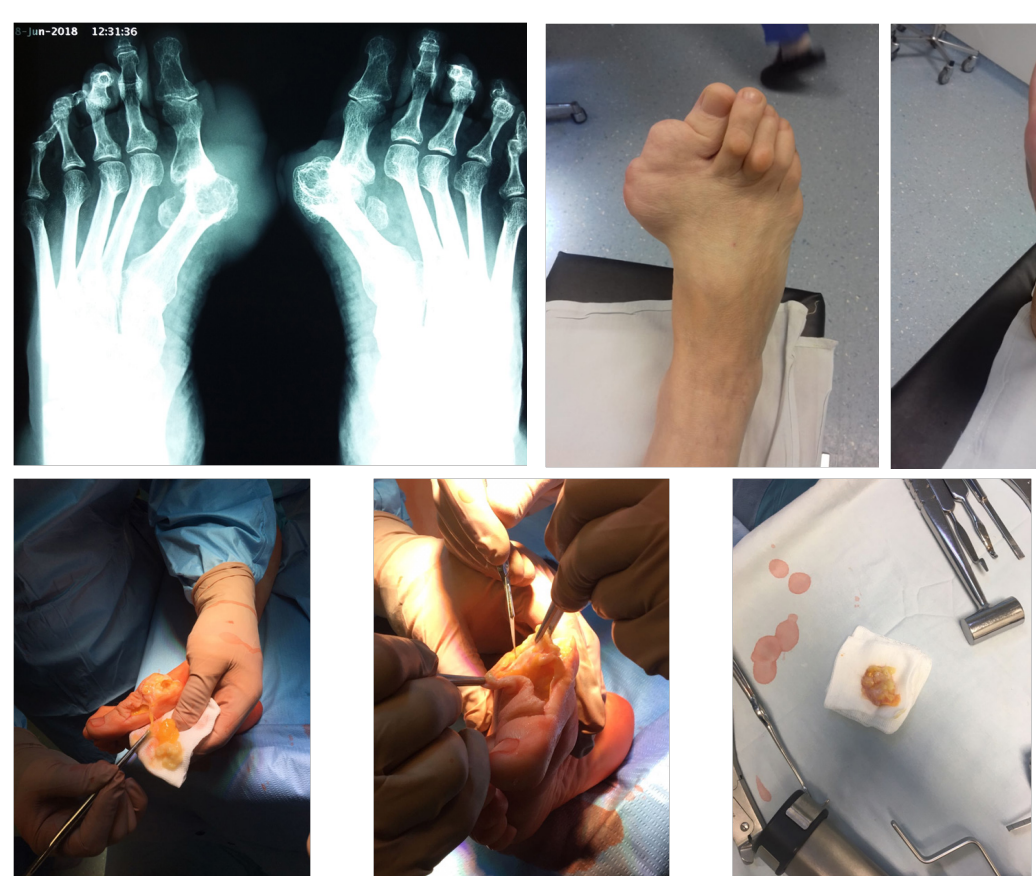

Volume 3 Issue 5 - 2018

\author{
Nurmukhametov MR, Logunov AL, Makarov \\ SA, Makarov MA \\ Designation orthopedist, VA Nasonova Institute of \\ Rheumatology, Russia
}

\begin{abstract}
Correspondence: Nurmukhametov Maxim, Designation orthopedist, University VA Nasonova Research Institute of Rheumatology, Address I I 5522, Kashirskoye sh, 34, Moscow, Russia, Tel+79166451885, Email nurmi91@mail.ru
\end{abstract}

Received: October 02, 2018 | Published: October 08, 2018

visualized, removed and taken for histological examination. Proximal phalanx of the first toe was in a subluxation, joint cartilage was absent. The articular ends were processed with the help of the oscillator saw. The arthrodesis was fixed in the correct position using $3 \mathrm{~K}$-wires due to the low density of the bone tissue and the presence of the bone cysts. After that the resection of the $2^{\text {nd }}$ and $3^{\text {rd }}$ toes bocks was performed, and toes were fixed with $\mathrm{K}$-wires.

\section{Post-operative management}

antibiotics during 5 days after the operation; pain management (Ketoprophenum + Promedolum -2 days, then - non-steroidal antiinflammatory drugs-on demand); removal of $\mathrm{K}$-wires from $2^{\text {nd }}$ and $3^{\text {rd }}$ toes -3 weeks after the operation; from $1^{\text {st }}$ toe -8 weeks after the operation; wearing the Barook shoes until the removal of all K-wires, then - using the individual insoles (Figure 1).
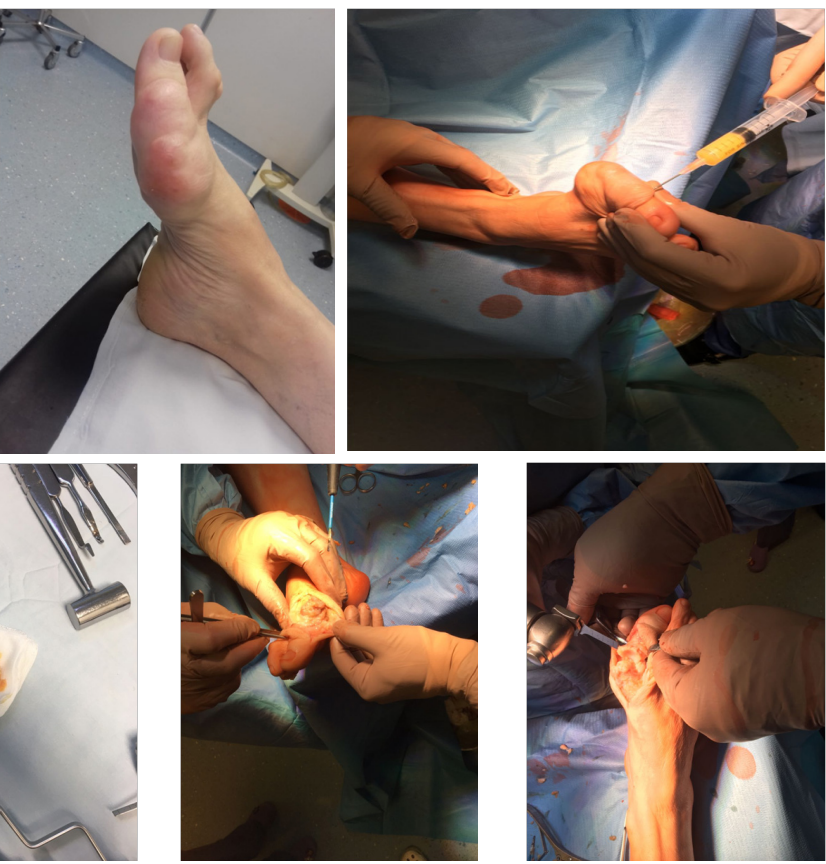

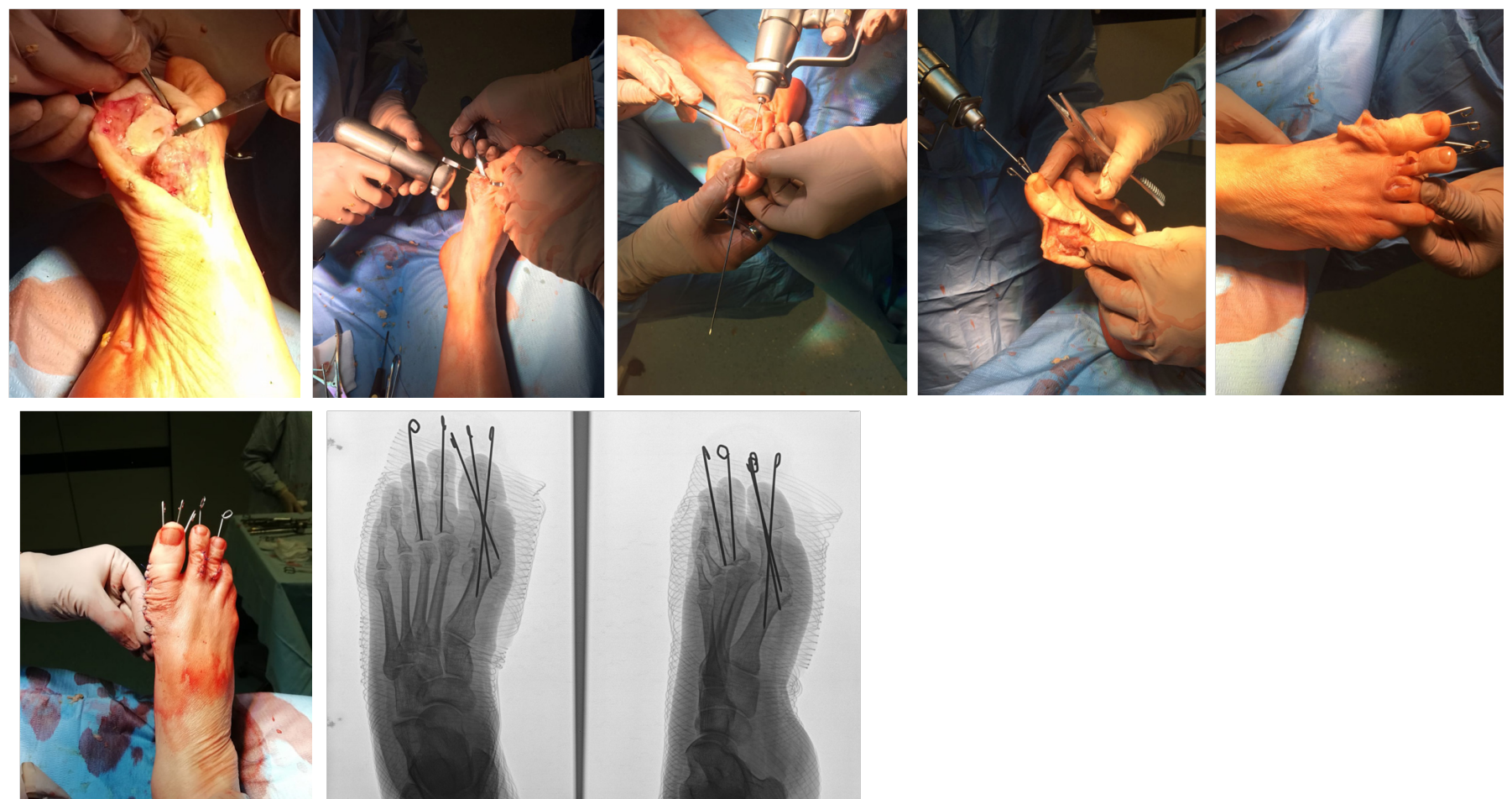

Figure I The cytological and histological examinations showed the signs of inflammatory process due to rheumatoid arthritis.

\section{Funding}

There is no funding source.

\section{Informed consent}

Informed consent was obtained.

\section{Acknowledgements}

None.

\section{Conflict of interest}

The authors declare that they have no conflict of interest. 